\title{
Crystallization and hydrolytic/thermal degradation of a novel stereocomplexationable blend of poly(L-2-hydroxybutyrate) and poly(D-2-hydroxybutyrate)
}

\author{
Hideto Tsuji and Ayaka Okumura
}

The maximum radial growth rate of spherulites of the novel stereocomplexationable blend of poly(L-2-hydroxybutyrate) $(\mathrm{P}(\mathrm{L}-\mathrm{B} \mathrm{HB}))$ and poly(D-2-hydroxybutyrate) $(\mathrm{P}(\mathrm{D}-2 \mathrm{HB})$ ) was observed to be substantially higher than those of pure $\mathrm{P}(\mathrm{L}-2 \mathrm{HB})$ and $\mathrm{P}(\mathrm{D}-2 \mathrm{HB})$. The hydrolytic degradation rate of the $\mathrm{P}(\mathrm{L}-2 \mathrm{HB}) / \mathrm{P}(\mathrm{D}-2 \mathrm{HB})$ blend traced by gravimetry and gel permeation chromatography was significantly lower than those of pure $\mathrm{P}(\mathrm{L}-2 \mathrm{HB})$ and $\mathrm{P}(\mathrm{D}-2 \mathrm{HB})$; this indicated that the blend had higher resistance to hydrolytic degradation. Further, the thermal degradation rate of the $\mathrm{P}(\mathrm{L}-2 \mathrm{HB}) / \mathrm{P}(\mathrm{D}-2 \mathrm{HB})$ blend was retarded as compared with those of pure $\mathrm{P}(\mathrm{L}-2 \mathrm{HB})$ and $\mathrm{P}(\mathrm{D}-2 \mathrm{HB})$. The results obtained in the present study indicate that the intermolecular interaction between $\mathrm{P}(\mathrm{L}-2 \mathrm{HB})$ and $\mathrm{P}(\mathrm{D}-2 \mathrm{HB})$ chains having opposite configurations in the amorphous regions or in the molten state was higher than that between $\mathrm{P}(\mathrm{L}-2 \mathrm{HB})$ or $\mathrm{P}(\mathrm{D}-2 \mathrm{HB})$ chains with the same configurations. The information obtained in the present study should be very useful for designing and processing pure, biodegradable materials of $\mathrm{P}(\mathrm{L}-2 \mathrm{HB}), \mathrm{P}(\mathrm{D}-2 \mathrm{HB})$ and their blends for biomedical, pharmaceutical and environmental applications.

Polymer Journal (2011) 43, 317-324; doi:10.1038/pj.2010.133; published online 22 December 2010

Keywords: crystallization; hydrolytic degradation; poly(hydroxybutanoic acid); poly(hydroxybutyric acid); stereocomplex; thermal degradation

\section{INTRODUCTION}

Poly(L-lactide) (that is, poly(L-lactic acid) or PLLA) is a biodegradable polymer produced from plant-derived renewable resources and is now used for biomedical, pharmaceutical, environmental, industrial and commercial applications. ${ }^{1-15}$ Stereocomplexation between PLLA and its enantiomer poly(D-lactide) (that is, poly(D-lactic acid) or PDLA) can yield biodegradable materials having superior mechanical performance and resistance to hydrolytic and thermal degradation relative to pure PLLA and PDLA. ${ }^{16-20}$

Poly(2-hydroxybutyrate) (that is, poly(2-hydroxybutanoic acid) or $\mathrm{P}(2 \mathrm{HB})$ ) is a biodegradable polymer with the structure of a poly(lactide) (that is, poly(lactic acid) or PLA) in which methyl groups are substituted with ethyl groups. A stereocomplex can also be formed by blending substituted enantiomeric PLAs, that is, poly(L-2-hydroxybutyrate) $[\mathrm{P}(\mathrm{L}-2 \mathrm{HB})]$ and poly(D-2-hydroxybutyrate $)(\mathrm{P}(\mathrm{D}-2 \mathrm{HB})) .{ }^{21}$ The melting temperature $\left(T_{\mathrm{m}}\right)$ of the $\mathrm{P}(\mathrm{L}-2 \mathrm{HB}) / \mathrm{P}(\mathrm{D}-2 \mathrm{HB})$ stereocomplex (ca. $200^{\circ} \mathrm{C}$ ) is higher than those of pure $\mathrm{P}(\mathrm{L}-2 \mathrm{HB})$ and $\mathrm{P}(\mathrm{D}-2 \mathrm{HB})$ (ca. $\left.100^{\circ} \mathrm{C}\right)$. The spherulite growth or crystallization of the $\mathrm{P}(\mathrm{L}-2 \mathrm{HB}) /$ $\mathrm{P}(\mathrm{D}-2 \mathrm{HB})$ stereocomplex is completed in a substantially shorter period of time as compared with those of pure $\mathrm{P}(\mathrm{L}-2 \mathrm{HB})$ and $\mathrm{P}(\mathrm{D}-2 \mathrm{HB})$. From the results reported for PLLA/PDLA blends, ${ }^{16-20}$ it is expected that the resistance of $\mathrm{P}(\mathrm{L}-2 \mathrm{HB}) / \mathrm{P}(\mathrm{D}-2 \mathrm{HB})$ blends to hydrolytic and thermal degradation should be higher than those of pure $\mathrm{P}(\mathrm{L}-2 \mathrm{HB})$ and $\mathrm{P}(\mathrm{D}-2 \mathrm{HB})$. Moreover, optically pure $\mathrm{P}(2 \mathrm{HB})$ can form a heterostereocomplex with non-substituted PLA having a configuration opposite to that of $\mathrm{P}(2 \mathrm{HB}),{ }^{22}$ whereas optically pure phenyl-substituted PLA is reported to have a higher intermolecular interaction with non-substituted PLA having a configuration opposite to that of phenyl-substituted PLA. ${ }^{23}$ However, to the best of our knowledge, there are no detailed reports on the crystallization or hydrolytic and thermal degradation behavior of $\mathrm{P}(\mathrm{L}-2 \mathrm{HB}) / \mathrm{P}(\mathrm{D}-2 \mathrm{HB})$ blends, although such information is crucial for designing and processing biodegradable stereocomplexationable $\mathrm{P}(\mathrm{L}-2 \mathrm{HB}) / \mathrm{P}(\mathrm{D}-2 \mathrm{HB})$ blends for biomedical, pharmaceutical and environmental applications.

This article is the first to report the detailed crystallization and hydrolytic and thermal degradation behavior of the novel stereocomplexationable $\mathrm{P}(\mathrm{L}-2 \mathrm{HB}) / \mathrm{P}(\mathrm{D}-2 \mathrm{HB})$ blend, relative to those of pure $\mathrm{P}(\mathrm{L}-2 \mathrm{HB})$ and $\mathrm{P}(\mathrm{D}-2 \mathrm{HB})$. For this purpose, the spherulite growth behavior of the specimens was traced using polarized optical microscopy; the specimens that were hydrolytically degraded in a phosphate-buffered solution at $80^{\circ} \mathrm{C}$ were studied using gravimetry, gel permeation chromatography (GPC) and differential scanning calorimetry (DSC); and the thermal degradation of the specimens was traced using thermogravimetry (TG). The crystallization and hydrolytic and 
thermal degradation of biodegradable crystalline polymers takes place in the melt or in the amorphous regions. Therefore, studying these phenomena reveals information about the intermolecular interaction between $\mathrm{P}(2 \mathrm{HB})$ having opposite and identical configurations. The information obtained in the present study can be effectively utilized for designing and processing biodegradable materials of pure $\mathrm{P}(\mathrm{L}-2 \mathrm{HB}), \mathrm{P}(\mathrm{D}-2 \mathrm{HB})$ and their blends for biomedical, pharmaceutical and environmental applications.

\section{MATERIALS AND METHODS}

\section{Materials}

$\mathrm{P}(\mathrm{L}-2 \mathrm{HB})$ and $\mathrm{P}(\mathrm{D}-2 \mathrm{HB})$ were synthesized by the polycondensation of $(\mathrm{S})$ - and (R)-2-hydroxybutanoic acids (2-hydroxybutyric acids) ( $\geqslant 97.0 \%$, enantiomeric ratio $\geqslant 99: 1$, Sigma-Aldrich (Tokyo, Japan)), respectively, ${ }^{24}$ following which purification and drying ${ }^{21,25}$ were carried out according to previous literature. The specimens (thickness of ca. $50 \mu \mathrm{m}$ ) used for the crystallization and hydrolytic and thermal degradation experiments were prepared according to the literature. ${ }^{21}$ Each solution of the purified and dried $\mathrm{P}(\mathrm{L}-2 \mathrm{HB})$ and $\mathrm{P}(\mathrm{D}-2 \mathrm{HB})$ was separately prepared with dichloromethane as the solvent to obtain a polymer concentration of $1 \mathrm{~g} \mathrm{dl}^{-1}$. For the preparation of $\mathrm{P}(\mathrm{L}-2 \mathrm{HB}) / \mathrm{P}(\mathrm{D}-2 \mathrm{HB})$ blend specimens, the $\mathrm{P}(\mathrm{L}-2 \mathrm{HB})$ and $\mathrm{P}(\mathrm{D}-2 \mathrm{HB})$ solutions were mixed with each other equimolarly under vigorous stirring. The solution was cast onto a petri-dish, followed by solvent evaporation at $25^{\circ} \mathrm{C}$ for approximately 1 day. Pure $\mathrm{P}(\mathrm{L}-2 \mathrm{HB})$ and $\mathrm{P}(\mathrm{D}-2 \mathrm{HB})$ specimens were also prepared by the same procedure without mixing solutions. The solvent remaining in the as-cast specimens was removed under reduced pressure for at least 7 days, and stored in a desiccator before the crystallization or hydrolytic and thermal degradation experiments. The pure $\mathrm{P}(\mathrm{L}-$ $2 \mathrm{HB})$ and $\mathrm{P}(\mathrm{D}-2 \mathrm{HB})$ specimens and blend specimens obtained in this manner were transparent and opaque films, respectively.

\section{Hydrolytic degradation}

The hydrolytic degradation of each of the specimens ( $8 \mathrm{mg}$ of dry weight) was performed for predetermined periods of time in $10 \mathrm{ml}$ of phosphate-buffered solution ( $\mathrm{pH}=7.4 \pm 0.1$ ) containing $0.02 \mathrm{wt} \%$ sodium azide at $80{ }^{\circ} \mathrm{C}$. The phosphate-buffered solution was replaced with a fresh one every 2 days. After hydrolytic degradation, the specimens were rinsed thrice with fresh distilled water at room temperature, following which they were dried under reduced pressure for at least 2 weeks. The distilled water used for preparation of the phosphate-buffered solution and rinsing of the hydrolytically degraded specimens was of high performance liquid chromatography (HPLC) grade (Nacalai Tesque, Kyoto, Japan).

\section{Physical measurements and observation}

The weight- and number-average molecular weights $\left(M_{\mathrm{w}}\right.$ and $M_{\mathrm{n}}$, respectively) of the specimens before and after hydrolytic degradation were evaluated in chloroform at $40^{\circ} \mathrm{C}$ using a Tosoh (Tosoh, Tokyo, Japan) GPC system (refractive index monitor: RI-8020) having two TSK Gel columns $\left(\mathrm{GMH}_{\mathrm{XL}}\right)$ using polystyrene standards. The glass transition and melting temperatures ( $T_{\mathrm{g}}$ and $T_{\mathrm{m}}$, respectively) and the melting enthalpies of homo-crystallites and stereocomplex crystallites $\left[\Delta H_{\mathrm{m}}(\mathrm{H})\right.$ and $\Delta H_{\mathrm{m}}(\mathrm{S})$, respectively] of the specimens were determined using a Shimadzu (Kyoto, Japan) DSC-50 differential scanning calorimeter. The specimens were heated at the rate of $10^{\circ} \mathrm{C} \mathrm{min}{ }^{-1}$ under a nitrogen gas flow of $50 \mathrm{ml} \mathrm{min}^{-1}$ for DSC measurements. The values of $T_{\mathrm{g}}, T_{\mathrm{m}}, \Delta H_{\mathrm{m}}(\mathrm{H})$ and $\Delta H_{\mathrm{m}}(\mathrm{S})$ of the specimens were calibrated using tin, indium and benzophenone as standards. Wide-angle X-ray scattering was performed at $25^{\circ} \mathrm{C}$ using a Rigaku (Tokyo, Japan) RINT-2500 equipped with a Cu-K $\alpha$ source $(\lambda=0.1542 \mathrm{~nm})$. The spherulite growth in the specimens was observed using an Olympus (Tokyo, Japan) polarized optical microscope (BX50) equipped with a Linkam (Surrey, UK) heating-cooling stage (LK$600 \mathrm{PM}$ ) under a constant nitrogen gas flow. The specimens were first heated at $100{ }^{\circ} \mathrm{C} \mathrm{m^{-1 }}$ to $240{ }^{\circ} \mathrm{C}$, maintained at the same temperature for $5 \mathrm{~min}$, and then cooled at $100{ }^{\circ} \mathrm{C} \mathrm{min}^{-1}$ to an arbitrary $T_{\mathcal{c}}$; the spherulite growth was observed at the same temperature. The thermal degradation behavior of the specimens was monitored using a Shimadzu DTG-50 under a nitrogen gas flow of $50 \mathrm{ml} \mathrm{min}^{-1}$.

\section{RESULTS}

\section{Crystallization}

The behavior, rate and mechanism of hydrolytic degradation of biodegradable polymers, including $\mathrm{P}(\mathrm{L}-2 \mathrm{HB})$ and $\mathrm{P}(\mathrm{D}-2 \mathrm{HB})$, can be controlled to some extent by varying the highly ordered structures formed during crystallization. Figure 1 shows the typical polarized optical photomicrographs of pure $\mathrm{P}(\mathrm{L}-2 \mathrm{HB})$ and a $\mathrm{P}(\mathrm{L}-2 \mathrm{HB}) /$ $\mathrm{P}(\mathrm{D}-2 \mathrm{HB})$ blend crystallized from the melt. Here, the photographs of pure $\mathrm{P}(\mathrm{D}-2 \mathrm{HB})$ are not shown, because its morphology was very similar to that of pure $\mathrm{P}(\mathrm{L}-2 \mathrm{HB})$. Considering the fact that the crystallization temperature $\left(T_{\mathrm{C}}\right)$ of the $\mathrm{P}(\mathrm{L}-2 \mathrm{HB}) / \mathrm{P}(\mathrm{D}-2 \mathrm{HB})$ blend was much higher than the $T_{\mathrm{m}}$ of pure $\mathrm{P}(\mathrm{L}-2 \mathrm{HB})$ and $\mathrm{P}(\mathrm{D}-2 \mathrm{HB})$ (ca. $\left.100^{\circ} \mathrm{C}\right)$, the crystallites formed in the $\mathrm{P}(\mathrm{L}-2 \mathrm{HB}) / \mathrm{P}(\mathrm{D}-2 \mathrm{HB})$ blend should be stereocomplex crystallites. The size of the stereocomplex spherulites increased with $T_{\mathrm{c}}$. This trend is consistent with that of the spherulites of the PLA stereocomplex and pure PLLA ${ }^{25-28}$ and is based on the decrease in the number of spherulite nuclei per unit mass with an increase in $T_{\mathrm{c}}$ or decrease in the degree of supercooling $\left(\Delta T=T_{\mathrm{m}}-\right.$ $T_{\mathrm{c}}$ ). Using the $T_{\mathrm{m}}$ values of as-cast specimens (Table 1 ), the $\Delta T$ values were calculated and are listed in the caption of Figure 1. Although $\Delta T=46.1^{\circ} \mathrm{C}$ of the $\mathrm{P}(\mathrm{L}-2 \mathrm{HB}) / \mathrm{P}(\mathrm{D}-2 \mathrm{HB})$ blend at $T_{\mathrm{C}}=170^{\circ} \mathrm{C}$ (Figure 1c) is higher than the $\Delta T=32.6^{\circ} \mathrm{C}$ of the pure $\mathrm{P}(\mathrm{L}-2 \mathrm{HB})$ at $T_{\mathrm{c}}=70^{\circ} \mathrm{C}$ (Figure 1a), the spherulite size was larger for the $\mathrm{P}(\mathrm{L}-2 \mathrm{HB}) /$ $\mathrm{P}(\mathrm{D}-2 \mathrm{HB})$ blend than for pure $\mathrm{P}(\mathrm{L}-2 \mathrm{HB})$. A similar tendency was observed in the $\mathrm{P}(\mathrm{L}-2 \mathrm{HB}) / \mathrm{P}(\mathrm{D}-2 \mathrm{HB})$ blend at $T_{\mathrm{c}}=195^{\circ} \mathrm{C}(\Delta T=$ $21.1^{\circ} \mathrm{C}$, Figure $\left.1 \mathrm{~d}\right)$ and in pure $\mathrm{P}(\mathrm{L}-2 \mathrm{HB})$ at $T_{\mathrm{c}}=90^{\circ} \mathrm{C}\left(\Delta T=12.6^{\circ} \mathrm{C}\right.$, Figure 1b). Maltese crosses were observed in the spherulites, with the exception of the spherulites of pure $\mathrm{P}(\mathrm{L}-2 \mathrm{HB})$ crystallized at $T_{\mathrm{c}}=70^{\circ} \mathrm{C}$, reflecting the regular orientation of lamellae in the spherulites. Such information could not be obtained for spherulites of pure $\mathrm{P}(\mathrm{L}-2 \mathrm{HB})$ crystallized at $T_{\mathrm{C}}=70^{\circ} \mathrm{C}$ because of their extremely small size.

The radial growth rates of spherulites $(G)$ and the induction periods for spherulite growth $\left(t_{\mathrm{i}}\right)$ of pure $\mathrm{P}(\mathrm{L}-2 \mathrm{HB}), \mathrm{P}(\mathrm{D}-2 \mathrm{HB})$ and their blend were estimated from the polarized optical photomicrographs; these are plotted in Figures $2 \mathrm{a}$ and $\mathrm{b}$ as a function of $T_{\mathrm{c}}$. Here, the $t_{\mathrm{i}}$ values were evaluated from extrapolation of the spherulite radius plotted against crystallization time to a radius of $0 \mu \mathrm{m}$. The $G$ values of pure $\mathrm{P}(\mathrm{L}-2 \mathrm{HB})$ and $\mathrm{P}(\mathrm{D}-2 \mathrm{HB})$ had maximum values $\left(1.6\right.$ and $1.7 \mu \mathrm{m} \mathrm{min}^{-1}$, respectively) when $T_{\mathrm{c}}$ was approximately $80^{\circ} \mathrm{C}$, whereas that of the $\mathrm{P}(\mathrm{L}-2 \mathrm{HB}) / \mathrm{P}(\mathrm{D}-2 \mathrm{HB})$ blend $\left(12 \mu \mathrm{m} \mathrm{min}^{-1}\right)$ was observed when $T_{\mathrm{c}}$ was approximately $170^{\circ} \mathrm{C}$. The maximum $G$ value of the latter is much higher than those of the former. This trend is consistent with the $G$ values reported for the PLLA/PDLA stereocomplex. ${ }^{25,29,30}$ In the case of the $\mathrm{P}(\mathrm{L}-2 \mathrm{HB}) / \mathrm{P}(\mathrm{D}-2 \mathrm{HB})$ blend, the $G$ values could become higher at a value of $T_{\mathrm{c}}$ below $170^{\circ} \mathrm{C}$. However, these $G$ values could not be estimated because of the extremely small $t_{\mathrm{i}}$ values for values of $T_{\mathrm{c}}$ above $170{ }^{\circ} \mathrm{C}$, which induced extremely rapid crystallization during cooling from the molten state to a predetermined value of $T_{\mathrm{c}}$ that was below $170^{\circ} \mathrm{C}$. The maximum $G$ value of the $\mathrm{P}(\mathrm{L}-2 \mathrm{HB}) /$ $\mathrm{P}(\mathrm{D}-2 \mathrm{HB})$ blend was approximately $12 \mu \mathrm{m} \mathrm{min}^{-1}$, which is more than seven times those of pure $\mathrm{P}(\mathrm{L}-2 \mathrm{HB})$ and $\mathrm{P}(\mathrm{D}-2 \mathrm{HB})$ (1.6 and $1.7 \mu \mathrm{m} \mathrm{min}^{-1}$, respectively). On the other hand, the $t_{\mathrm{i}}$ values of the $\mathrm{P}(\mathrm{L}-2 \mathrm{HB}) / \mathrm{P}(\mathrm{D}-2 \mathrm{HB})$ blend were practically zero for a value of $T_{\mathrm{c}}$ in the range of $170-195^{\circ} \mathrm{C}$, whereas those of pure $\mathrm{P}(\mathrm{L}-2 \mathrm{HB})$ and $\mathrm{P}(\mathrm{D}-2 \mathrm{HB})$ gradually increased with $T_{\mathrm{c}}$ and finally became infinity when $T_{\mathrm{C}}$ approached $T_{\mathrm{m}}\left(100^{\circ} \mathrm{C}\right)$. The $G$ and $t_{\mathrm{i}}$ values are replotted in Figures $2 \mathrm{c}$ and $\mathrm{d}$ as a function of $\Delta T$. The $G$ values were higher for the $\mathrm{P}(\mathrm{L}-2 \mathrm{HB}) /$ $\mathrm{P}(\mathrm{D}-2 \mathrm{HB})$ blend than for pure $\mathrm{P}(\mathrm{L}-2 \mathrm{HB})$ and $\mathrm{P}(\mathrm{D}-2 \mathrm{HB})$, when compared at the same $\Delta T$ values. In contrast, the $t_{\mathrm{i}}$ values of all specimens exhibited a similar dependence on $\Delta T$. 



Figure 1 Polarized optical photomicrographs of pure $\mathrm{P}(\mathrm{L}-2 \mathrm{HB})$ crystallized at $T_{\mathrm{c}}=70^{\circ} \mathrm{C}\left(\Delta T=32.6^{\circ} \mathrm{C}\right)$ for $3 \mathrm{~min}(\mathrm{a})$, at $T_{\mathrm{c}}=90^{\circ} \mathrm{C}\left(\Delta T=12.6^{\circ} \mathrm{C}\right)$ for $12 \mathrm{~min}(\mathbf{b})$, and of the $\mathrm{P}(\mathrm{L}-2 \mathrm{HB}) / \mathrm{P}(\mathrm{D}-2 \mathrm{HB})$ blend crystallized at $T_{\mathrm{C}}=170^{\circ} \mathrm{C}\left(\Delta T=46.1^{\circ} \mathrm{C}\right)$ for $0.5 \mathrm{~min}(\mathrm{c})$, and at $T_{\mathrm{c}}=195^{\circ} \mathrm{C}\left(\Delta T=21.1{ }^{\circ} \mathrm{C}\right)$ for $7 \mathrm{~min}(\mathrm{~d})$.

Table 1 Characteristics and properties of pure $\mathrm{P}(\mathrm{L}-2 \mathrm{HB}), \mathrm{P}(\mathrm{D}-2 \mathrm{HB})$ and their blend before and after hydrolytic degradation

\begin{tabular}{|c|c|c|c|c|c|c|}
\hline Code & Degradation time (days) & $\mathrm{M}_{n}\left(\mathrm{gmol}^{-1}\right)^{\mathrm{a}}$ & $\mathrm{M}_{w} \mathrm{M}_{n}{ }^{\mathrm{a}}$ & $\mathrm{T}_{g}\left({ }^{\circ} \mathrm{C}\right)^{\mathrm{b}}$ & $\mathrm{T}_{m}\left({ }^{\mathrm{C} C}\right)^{\mathrm{b}}$ & $\Delta \mathrm{H}_{m}\left(J g^{-1}\right)^{\mathrm{b}}$ \\
\hline \multirow[t]{2}{*}{$\mathrm{P}(\mathrm{L}-2 \mathrm{HB})$} & 0 & $1.67 \times 10^{4}$ & 1.57 & 25.3 & 102.6 & 22.6 \\
\hline & 16 & $3.06 \times 10^{3}$ & 2.57 & 23.9 & 105.7 & 24.9 \\
\hline$P(D-2 H B)$ & 16 & $3.02 \times 10^{3}$ & 2.64 & 26.0 & 108.6 & 38.7 \\
\hline \multirow[t]{2}{*}{$\mathrm{P}(\mathrm{L}-2 \mathrm{HB}) / \mathrm{P}(\mathrm{D}-2 \mathrm{HB})$} & 0 & $1.51 \times 10^{4}$ & 1.58 & 43.6 & 216.1 & 67.5 \\
\hline & 16 & $4.80 \times 10^{3}$ & 2.17 & $-^{c}$ & 212.8 & 75.5 \\
\hline
\end{tabular}

Abbreviations: $\mathrm{P}(\mathrm{D}-2 \mathrm{HB})$, poly(D-2-hydroxybutyrate); $\mathrm{P}(\mathrm{L}-2 \mathrm{HB})$, poly(L-2-hydroxybutyrate).

a $M_{\mathrm{n}}$ and $M_{\mathrm{n}}$ are number- and weight-average molecular weights, respectively.

${ }^{\mathrm{b}} T_{\mathrm{g}}, T_{\mathrm{m}}$ and $\Delta H_{\mathrm{m}}$ are glass transition and melting temperatures and enthalpy of melting, respectively.

'Glass transition was not clear to estimate the transition temperature.

\section{Hydrolytic degradation}

The hydrolytic degradation rate, behavior and mechanism of $\mathrm{P}(\mathrm{L}-2 \mathrm{HB})$ and $\mathrm{P}(\mathrm{D}-2 \mathrm{HB})$ are of great importance, especially when these polymers are used as biomedical, pharmaceutical and environmental materials. The hydrolytic degradation rates of the $\mathrm{P}(2 \mathrm{HB})$ specimens are assumed to be lower than those of PLA specimens; therefore, a long time is required for their complete degradation at a low temperature. We accordingly carried out accelerated hydrolytic degradation at an elevated temperature of $80^{\circ} \mathrm{C}$. Figure 3 shows the wide-angle X-ray scattering profiles of pure $\mathrm{P}(\mathrm{L}-2 \mathrm{HB}), \mathrm{P}(\mathrm{D}-2 \mathrm{HB})$ and their blend before and after hydrolytic degradation for 20 days at $80^{\circ} \mathrm{C}$. Before hydrolytic degradation, pure $\mathrm{P}(\mathrm{L}-2 \mathrm{HB})$ and $\mathrm{P}(\mathrm{D}-2 \mathrm{HB})$ had intense crystalline diffraction peaks at around $15^{\circ}$ and $17^{\circ}$, whereas the $\mathrm{P}(\mathrm{L}-2 \mathrm{HB}) / \mathrm{P}(\mathrm{D}-2 \mathrm{HB})$ blend exhibited no such peaks for pure $\mathrm{P}(\mathrm{L}-2 \mathrm{HB})$ and $\mathrm{P}(\mathrm{D}-2 \mathrm{HB})$, with the exception of new crystalline peaks at around $11^{\circ}, 18^{\circ}$ and $22^{\circ}$, which are ascribed to stereocomplex crystalline peaks. ${ }^{21}$ After hydrolytic degradation, the specimens had crystalline peaks at the diffraction angles identical to those of the specimens before hydrolytic degradation. These findings reflect that the crystalline species were not altered by the hydrolytic degradation, and, therefore, the $\mathrm{P}(\mathrm{L}-2 \mathrm{HB}) / \mathrm{P}(\mathrm{D}-2 \mathrm{HB})$ blend contained only stereocomplex crystallites as crystalline species during hydrolytic degradation.

Figure 4 shows the percentage remaining weight of hydrolytically degraded pure $\mathrm{P}(\mathrm{L}-2 \mathrm{HB}), \mathrm{P}(\mathrm{D}-2 \mathrm{HB})$ and their blend as a function of degradation time. Loss of weight was observed for all specimens even at 4 days, indicating that water-soluble oligomers and monomers were formed and removed from the mother specimens. The remaining weight percentages of the $\mathrm{P}(\mathrm{L}-2 \mathrm{HB}) / \mathrm{P}(\mathrm{D}-2 \mathrm{HB})$ blend were higher than those of pure $\mathrm{P}(\mathrm{L}-2 \mathrm{HB})$ and $\mathrm{P}(\mathrm{D}-2 \mathrm{HB})$, when compared for the same hydrolytic degradation periods.

Figure 5 shows the GPC profiles of pure $\mathrm{P}(\mathrm{L}-2 \mathrm{HB}), \mathrm{P}(\mathrm{D}-2 \mathrm{HB})$ and their blend before and after hydrolytic degradation for 16 days. As seen in this figure, the molecular weight distribution curves of all specimens drastically shifted to a lower molecular weight, indicating that the hydrolytic degradation of the specimens occurs via a bulk erosion mechanism. This is consistent with the observations in the case of the hydrolytic degradation of PLA-based materials in neutral media. ${ }^{16,19,31-33}$ The $M_{\mathrm{n}}$ and $M_{\mathrm{w}} / M_{\mathrm{n}}$ of pure $\mathrm{P}(\mathrm{L}-2 \mathrm{HB}), \mathrm{P}(\mathrm{D}-2 \mathrm{HB})$ and their blend, after hydrolytic degradation for different periods, were estimated from the GPC profiles and are plotted in Figure 6 as a 



Figure 2 Radial growth rate of spherulites $(G)(\mathbf{a}, \mathbf{c})$ and induction period for spherulite growth $\left(t_{\mathrm{i}}\right)(\mathbf{b}$, d) of pure $\mathrm{P}(\mathrm{L}-2 \mathrm{HB}), \mathrm{P}(\mathrm{D}-2 \mathrm{HB})$ and their blend as functions of crystallization temperature $\left(T_{\mathrm{c}}\right)(\mathbf{a}, \mathbf{b})$ and degree of supercooling $(\Delta T)(\mathbf{c}, \mathbf{d})$.
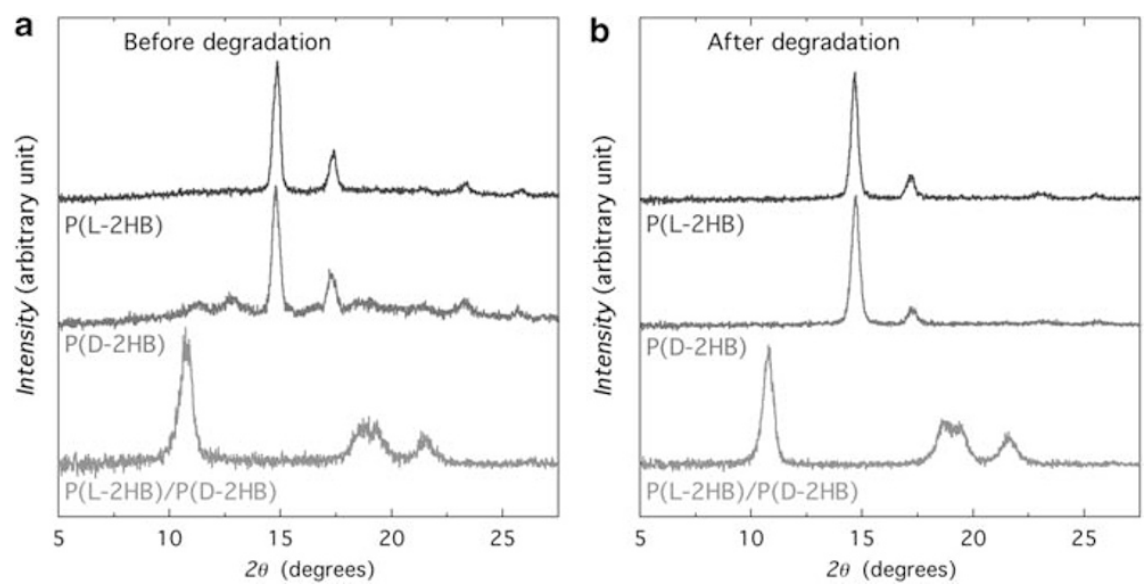

Figure 3 WAXS profiles of pure $\mathrm{P}(\mathrm{L}-2 \mathrm{HB}), \mathrm{P}(\mathrm{D}-2 \mathrm{HB})$ and their blend before (a) and after (b) hydrolytic degradation at $80^{\circ} \mathrm{C}$ for 20 days.

function of degradation time. The $M_{\mathrm{n}}$ values of pure $\mathrm{P}(\mathrm{L}-2 \mathrm{HB})$, $\mathrm{P}(\mathrm{D}-2 \mathrm{HB})$ and their blend decreased rapidly in the first 4,4 and 8 days, respectively, followed by a less rapid decrease after these periods. The $M_{\mathrm{n}}$ values were higher for the $\mathrm{P}(\mathrm{L}-2 \mathrm{HB}) / \mathrm{P}(\mathrm{D}-2 \mathrm{HB})$ blend than for pure $\mathrm{P}(\mathrm{L}-2 \mathrm{HB})$ and $\mathrm{P}(\mathrm{D}-2 \mathrm{HB})$, when compared for the same degradation periods. The remaining weight percentages and $M_{\mathrm{n}}$ values reflect that the $\mathrm{P}(\mathrm{L}-2 \mathrm{HB}) / \mathrm{P}(\mathrm{D}-2 \mathrm{HB})$ blend has a superior hydrolytic degradation resistance as compared with pure $\mathrm{P}(\mathrm{L}-2 \mathrm{HB})$ and $\mathrm{P}(\mathrm{D}-$ $2 \mathrm{HB})$; this is in agreement with the experimental results of hydrolytic degradation $^{16-19}$ and theoretical calculations ${ }^{34}$ for a PLLA/PDLA stereocomplex relative to pure PLLA and PDLA. The value of $M_{\mathrm{w}} / M_{\mathrm{n}}$ of pure $\mathrm{P}(\mathrm{L}-2 \mathrm{HB}), \mathrm{P}(\mathrm{D}-2 \mathrm{HB})$ and their blend increased in the first 8 days, followed by a decrease or plateau. The initial rapid decrease in $M_{\mathrm{n}}$ and increase in $M_{\mathrm{w}} / M_{\mathrm{n}}$ can be attributed to the rapid hydrolytic degradation and removal of chains in the amorphous regions. On the other hand, the less rapid decrease in $M_{\mathrm{n}}$ and the slow decrease or plateau of $M_{\mathrm{w}} / M_{\mathrm{n}}$ can be ascribed to the formation of crystalline residues and their slow degradation. 
Figure 7 shows the DSC thermograms of pure $\mathrm{P}(\mathrm{L}-2 \mathrm{HB}), \mathrm{P}(\mathrm{D}-2 \mathrm{HB})$ and their blend after being hydrolytically degraded for different periods of time. Before hydrolytic degradation, a single melting peak was observed at around 100 and $200^{\circ} \mathrm{C}$ for pure $\mathrm{P}(\mathrm{L}-2 \mathrm{HB})$ and the $\mathrm{P}(\mathrm{L}-2 \mathrm{HB}) / \mathrm{P}(\mathrm{D}-2 \mathrm{HB})$ blend, respectively, whereas double melting peaks were observed at 103 and $113{ }^{\circ} \mathrm{C}$ for pure $\mathrm{P}(\mathrm{D}-2 \mathrm{HB})$. The presence of double-melting endotherms at lower and higher temperatures can be attributed to the melting of original crystallites and those recrystallized during DSC heating, respectively. Therefore, the peak temperature of melting for the lower-temperature side should be the real value of $T_{\mathrm{m}}$. In the case of $\mathrm{P}(\mathrm{L}-2 \mathrm{HB})$, it is thought that well-grown or relatively perfect crystallites were formed during solvent evaporation and, therefore, no further crystallization and melting occurred during DSC heating. Changes in the $T_{\mathrm{m}}$ and $\Delta H_{\mathrm{m}}$ values of the specimens during hydrolytic degradation have been obtained from Figure 7 and are plotted in Figure 8 as a function of degradation time. The value of $T_{\mathrm{m}}$ for pure $\mathrm{P}(\mathrm{L}-2 \mathrm{HB})$ increased for a period of up to 8 days, but decreased for longer periods, whereas that of pure $\mathrm{P}(\mathrm{D}-2 \mathrm{HB})$ gradually increased for the entire period studied in this case. The value of $\Delta H_{\mathrm{m}}$ for pure $\mathrm{P}(\mathrm{L}-2 \mathrm{HB})$ and $\mathrm{P}(\mathrm{D}-2 \mathrm{HB})$ varied in a manner similar to their $T_{\mathrm{m}}$ value. The increase in $T_{\mathrm{m}}$ reflects the crystalline growth or decrease in lattice disorder, whereas the decrease in $T_{\mathrm{m}}$ indicates



Figure 4 Remaining weight percentages of pure $P(L-2 H B), P(D-2 H B)$ and their blend after being hydrolytically degraded at $80^{\circ} \mathrm{C}$ shown as a function of degradation time. a decrease in the crystalline thickness or structural change in the surface of the crystalline regions through hydrolytic degradation. As no cold crystallization peak was observed for any of the specimens, the increase in $\Delta H_{\mathrm{m}}$, except for that of pure $\mathrm{P}(\mathrm{L}-2 \mathrm{HB})$ for the period exceeding 12 days, indicates selective hydrolytic degradation and removal of chains in the amorphous regions in the first stage. On the other hand, in addition to the reduced $T_{\mathrm{m}}$, the decrease in $\Delta H_{\mathrm{m}}$ of pure $\mathrm{P}(\mathrm{L}-2 \mathrm{HB})$ for a period exceeding 12 days reflects the hydrolytic degradation of the crystalline regions or reduced crystalline thickness, which increases the surface area per unit mass of the crystalline regions and thereby reduces $\Delta H_{\mathrm{m}}$.

In contrast, the changes in $T_{\mathrm{m}}$ and $\Delta H_{\mathrm{m}}$ of the $\mathrm{P}(\mathrm{L}-2 \mathrm{HB}) / \mathrm{P}(\mathrm{D}-2 \mathrm{HB})$ blend are different from those of pure $\mathrm{P}(\mathrm{L}-2 \mathrm{HB})$ and $\mathrm{P}(\mathrm{D}-2 \mathrm{HB})$. That is, the decrease in the value of $T_{\mathrm{m}}$ took place from 4 th days without an initial increase and then continued for the entire period, whereas the value of $\Delta H_{\mathrm{m}}$ increased gradually for the entire period. The former indicates a decrease in the crystalline thickness or the surface structural change of the crystalline regions even in the first stage, while the latter indicates a predominant hydrolytic degradation of the amorphous regions compared with that of the crystalline regions. Considering the gradual increase in $\Delta H_{\mathrm{m}}$, the decrease in the value of $T_{\mathrm{m}}$ can be ascribed to the structural change in the surface of the crystalline regions, but not to the reduction in the crystalline thickness. Such a change in the value of $T_{m}$ for the $\mathrm{P}(\mathrm{L}-2 \mathrm{HB}) / \mathrm{P}(\mathrm{D}-2 \mathrm{HB})$ blend upon hydrolytic degradation was observed for the PLLA/PDLA stereocomplex at hydrolytic degradation temperatures in the range of $50-97^{\circ}$ C..$^{19}$

\section{Thermal degradation}

Biodegradable polyesters including $\mathrm{P}(\mathrm{L}-2 \mathrm{HB})$ and $\mathrm{P}(\mathrm{D}-2 \mathrm{HB})$ are susceptible to thermal degradation. Therefore, basic information about thermal degradation is crucial for determining their thermal processing conditions. Figure 9 shows the typical thermogravimetric curves of pure $\mathrm{P}(\mathrm{L}-2 \mathrm{HB}), \mathrm{P}(\mathrm{D}-2 \mathrm{HB})$ and their blend during the process of heating from room temperature. The remaining weight percentages of all specimens started to decrease above $260^{\circ} \mathrm{C}$ and finally reached zero at approximately $360{ }^{\circ} \mathrm{C}$. Although the thermal degradation temperature range is higher than the melting temperature range, the remaining weight percentage of the $\mathrm{P}(\mathrm{L}-2 \mathrm{HB}) / \mathrm{P}(\mathrm{D}-2 \mathrm{HB})$ blend decreased slowly as compared with those of pure $\mathrm{P}(\mathrm{L}-2 \mathrm{HB})$ and $\mathrm{P}(\mathrm{D}-2 \mathrm{HB})$, indicating the high thermal stability of the blend. This finding is consistent with the result reported for the PLLA/PDLA stereocomplex in comparison with pure PLLA and PDLA. ${ }^{20}$ However, in the case of the PLLA/PDLA stereocomplex, the difference in thermal degradation behavior was only monitored when the specimens were retained at
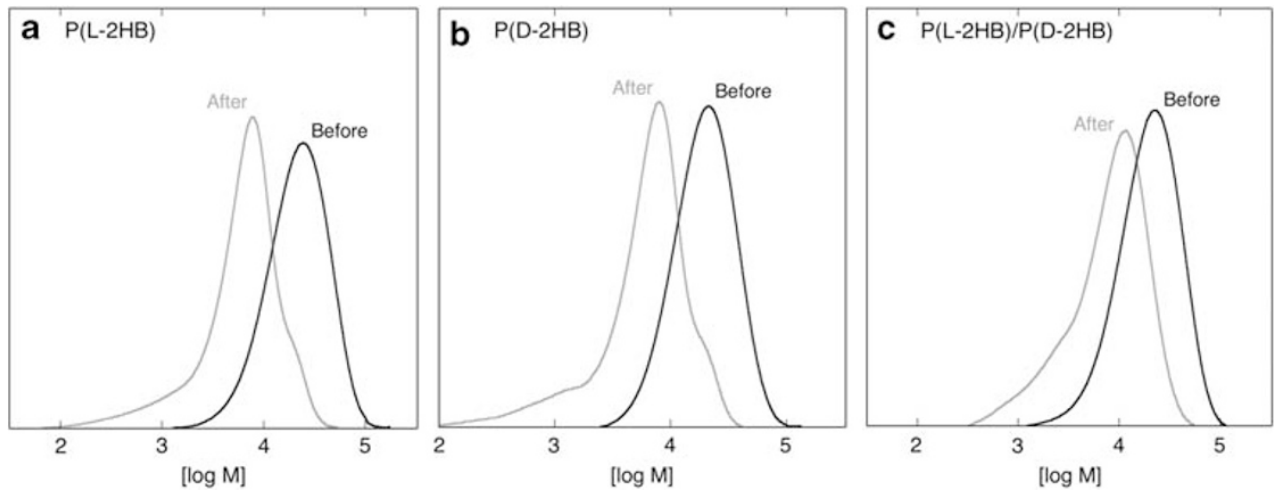

Figure 5 GPC profiles of pure $\mathrm{P}(\mathrm{L}-2 \mathrm{HB})(\mathbf{a}), \mathrm{P}(\mathrm{D}-2 \mathrm{HB})(\mathbf{b})$ and their blend (c) before (day 0 ) and after hydrolytic degradation at $80^{\circ} \mathrm{C}$ for 16 days. 



Figure $6 M_{\mathrm{n}}(\mathrm{a})$ and $M_{\mathrm{w}} / M_{\mathrm{n}}(\mathbf{b})$ of pure $\mathrm{P}(\mathrm{L}-2 \mathrm{HB})(\mathrm{a}), \mathrm{P}(\mathrm{D}-2 \mathrm{HB})$ and their blend, after being hydrolytically degraded at $80^{\circ} \mathrm{C}$, as a function of degradation time.
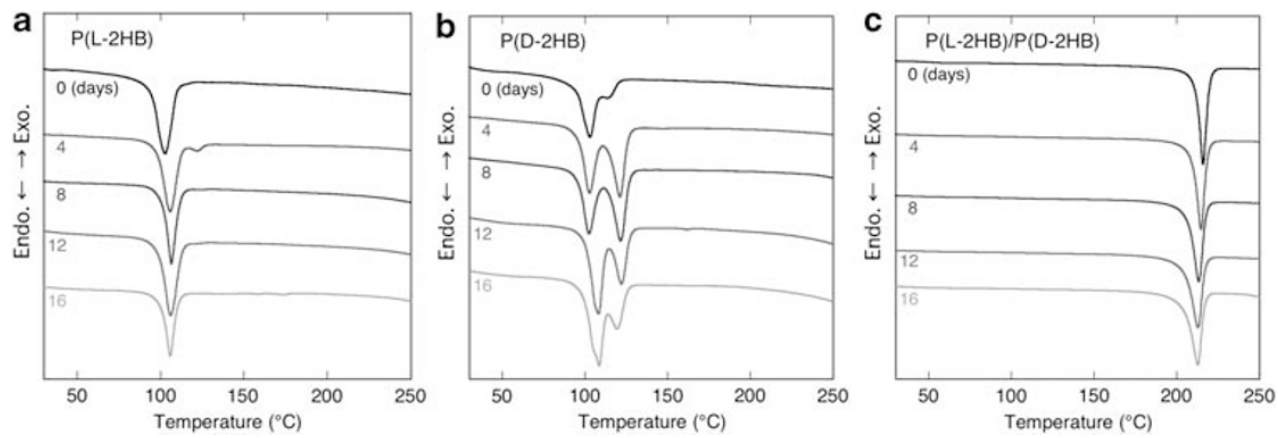

Figure 7 DSC thermograms of pure $\mathrm{P}(\mathrm{L}-2 \mathrm{HB})(\mathbf{a}), \mathrm{P}(\mathrm{D}-2 \mathrm{HB})$ (b) and their blend (c) after being hydrolytically degraded at $80^{\circ} \mathrm{C}$ for different degradation times.


Figure $8 T_{\mathrm{m}}$ (a) and $\Delta H_{\mathrm{m}}$ (b) of pure $\mathrm{P}(\mathrm{L}-2 \mathrm{HB}), \mathrm{P}(\mathrm{D}-2 \mathrm{HB})$ and their blend hydrolytically degraded at $80^{\circ} \mathrm{C}$, as a function of degradation time.

constant temperatures $\left(250\right.$ and $\left.260^{\circ} \mathrm{C}\right)$ just above $T_{\mathrm{m}}$, but not when the specimens were heated at the constantly increasing temperature.

The thermal degradation temperatures $\left(T_{\mathrm{td}}\right)$ were obtained for different remaining weight percentages, and the heating rate $(\phi)$ is plotted in Figure 10 as a function of $T_{\mathrm{td}}$. From the values of the slope shown in Figure 10, the activation energy values for thermal degradation $\left(\Delta E_{\mathrm{td}}\right)$ were obtained by the following equation derived by
Ozawa $^{35}$ and then plotted in Figure 11 as a function of the percentage weight loss.

$$
-\log \phi-0.4567 \Delta E_{\mathrm{td}} / R T_{\mathrm{td}}=\text { const., }
$$

where $R$ is the gas constant. The $\Delta E_{\mathrm{td}}$ values of pure $\mathrm{P}(\mathrm{L}-2 \mathrm{HB})$ and $\mathrm{P}(\mathrm{D}-2 \mathrm{HB})$ were in the ranges of $111-167$ and $107-158 \mathrm{~kJ} \mathrm{~mol}^{-1}$, respectively, whereas those of the $\mathrm{P}(\mathrm{L}-2 \mathrm{HB}) / \mathrm{P}(\mathrm{D}-2 \mathrm{HB})$ blend were in 
the range of $122-183 \mathrm{~kJ} \mathrm{~mol}^{-1}$. The $\Delta E_{\mathrm{td}}$ values are higher for the $\mathrm{P}(\mathrm{L}-2 \mathrm{HB}) / \mathrm{P}(\mathrm{D}-2 \mathrm{HB})$ blend than for pure $\mathrm{P}(\mathrm{L}-2 \mathrm{HB})$ and $\mathrm{P}(\mathrm{D}-2 \mathrm{HB})$, when compared for the same percentage weight losses, reflecting the higher thermal stability of the $\mathrm{P}(\mathrm{L}-2 \mathrm{HB}) / \mathrm{P}(\mathrm{D}-2 \mathrm{HB})$ blend. The difference in $\Delta E_{\mathrm{td}}$ values between the specimens was lowest at a percentage weight loss of $10 \mathrm{wt} \%$. The difference in $\Delta E_{\mathrm{td}}$ values between pure $\mathrm{P}(\mathrm{L}-2 \mathrm{HB})$ and $\mathrm{P}(\mathrm{D}-2 \mathrm{HB})$ can be ascribed to the differences in the molecular weight distribution and the fraction of monomer and oligomers.

\section{DISCUSSION}

The $G$ values of the $\mathrm{P}(\mathrm{L}-2 \mathrm{HB}) / \mathrm{P}(\mathrm{D}-2 \mathrm{HB})$ blend were much larger than those of pure $\mathrm{P}(\mathrm{L}-2 \mathrm{HB})$ and $\mathrm{P}(\mathrm{D}-2 \mathrm{HB})$, when compared for the same $\Delta T$ values. As a result of the crystallization in the melt, stereocomplex crystallites were formed in the $\mathrm{P}(\mathrm{L}-2 \mathrm{HB}) / \mathrm{P}(\mathrm{D}-2 \mathrm{HB})$ blend. Therefore, the larger $G$ values of the $\mathrm{P}(\mathrm{L}-2 \mathrm{HB}) / \mathrm{P}(\mathrm{D}-2 \mathrm{HB})$ blend indicate that the intermolecular interaction between the $\mathrm{P}(\mathrm{L}-2 \mathrm{HB})$ and $\mathrm{P}(\mathrm{D}-2 \mathrm{HB})$ chains having opposite configurations in the molten state is higher than that between the $\mathrm{P}(\mathrm{L}-2 \mathrm{HB})$ chains or the $\mathrm{P}(\mathrm{D}-2 \mathrm{HB})$ chains with the same configurations, resulting in the rapid growth of the $\mathrm{P}(\mathrm{L}-2 \mathrm{HB}) / \mathrm{P}(\mathrm{D}-2 \mathrm{HB})$ stereocomplex spherulites. On the other hand, the hydrolytic degradation of the $\mathrm{P}(\mathrm{L}-2 \mathrm{HB}) / \mathrm{P}(\mathrm{D}-2 \mathrm{HB})$ blend was retarded as compared with that of pure $\mathrm{P}(\mathrm{L}-2 \mathrm{HB})$ or $\mathrm{P}(\mathrm{D}-2 \mathrm{HB})$; the degradation was traced by gravimetry and GPC. The GPC and DSC

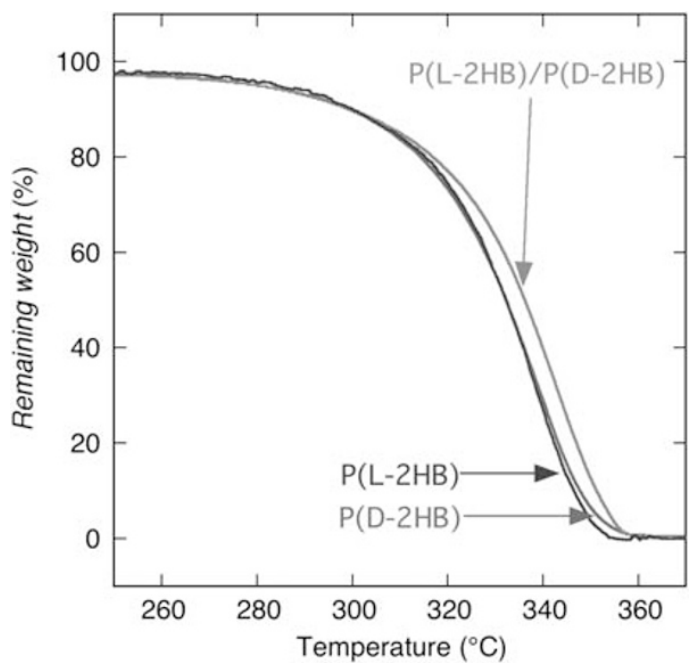

Figure 9 Remaining weight percentages of pure $\mathrm{P}(\mathrm{L}-2 \mathrm{HB}), \mathrm{P}(\mathrm{D}-2 \mathrm{HB})$ and their blend as a function of temperature (heating rate $=3{ }^{\circ} \mathrm{C} \mathrm{min}^{-1}$ ). data strongly suggested that the hydrolytic degradation for the period up to 16 days at $80^{\circ} \mathrm{C}$ is in the first stage, where hydrolytic degradation mainly occurred in the amorphous regions. Therefore, the delayed hydrolytic degradation of the $\mathrm{P}(\mathrm{L}-2 \mathrm{HB}) / \mathrm{P}(\mathrm{D}-2 \mathrm{HB})$ blend indicates that the intermolecular interaction between the $\mathrm{P}(\mathrm{L}-2 \mathrm{HB})$ and $\mathrm{P}(\mathrm{D}-2 \mathrm{HB})$ chains having opposite configurations in the amorphous regions is larger than that between the $\mathrm{P}(\mathrm{L}-2 \mathrm{HB})$ chains or the $\mathrm{P}(\mathrm{D}-2 \mathrm{HB})$ chains with the same configurations. This relatively large value of intermolecular interaction protects $\mathrm{P}(2 \mathrm{HB})$ chains in the blend from the hydrolytic cleavage. In addition, the thermal degradation of the $\mathrm{P}(\mathrm{L}-2 \mathrm{HB}) / \mathrm{P}(\mathrm{D}-2 \mathrm{HB})$ blend was retarded, and its $\Delta E_{\mathrm{td}}$ value was higher than those of pure $\mathrm{P}(\mathrm{L}-2 \mathrm{HB})$ and $\mathrm{P}(\mathrm{D}-2 \mathrm{HB})$. The thermal degradation of all specimens took place in the range of $260-360^{\circ} \mathrm{C}$, which is above the value of $T_{m}$ of the $\mathrm{P}(\mathrm{L}-2 \mathrm{HB}) / \mathrm{P}(\mathrm{D}-2 \mathrm{HB})$ stereocomplex (ca. $200{ }^{\circ} \mathrm{C}$ ). Considering this fact, the delayed thermal degradation of the $\mathrm{P}(\mathrm{L}-2 \mathrm{HB}) / \mathrm{P}(\mathrm{D}-2 \mathrm{HB})$ blend indicates that the intermolecular interaction between the $\mathrm{P}(\mathrm{L}-2 \mathrm{HB})$ and the $\mathrm{P}(\mathrm{D}-2 \mathrm{HB})$ chains having the opposite configurations in the molten state is higher than that between the $\mathrm{P}(\mathrm{L}-2 \mathrm{HB})$ chains or the $\mathrm{P}(\mathrm{D}-2 \mathrm{HB})$ chains with

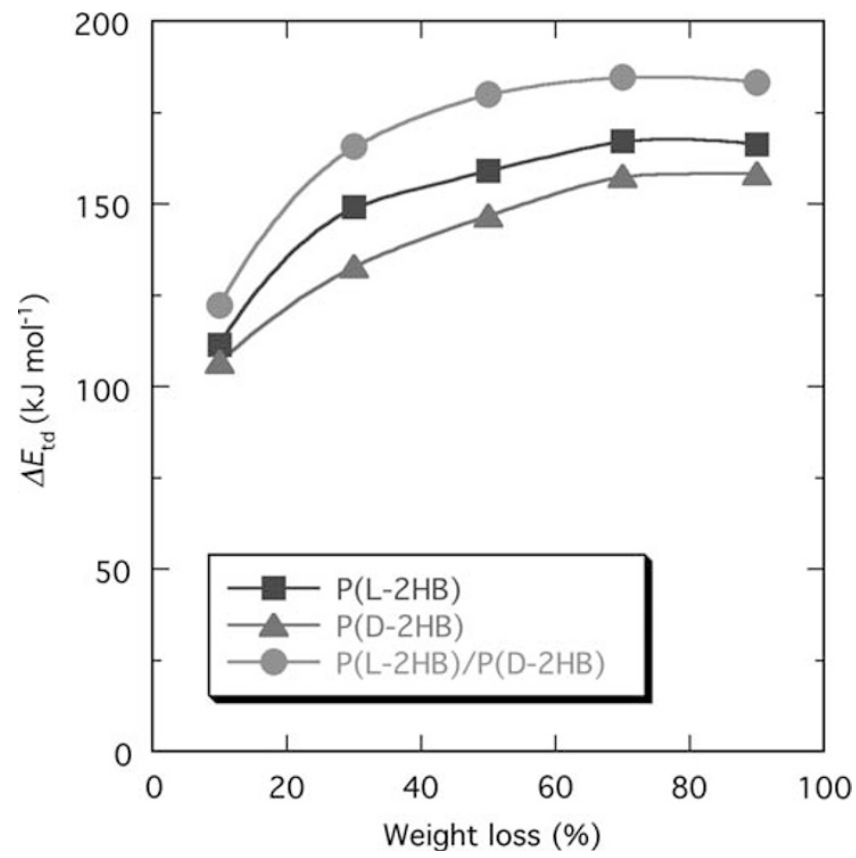

Figure 11 Activation energy for thermal degradation $\left(\Delta E_{\mathrm{td}}\right)$ of pure $\mathrm{P}(\mathrm{L}-2 \mathrm{HB})$, $\mathrm{P}(\mathrm{D}-2 \mathrm{HB})$ and their blend as a function of percentage weight loss.
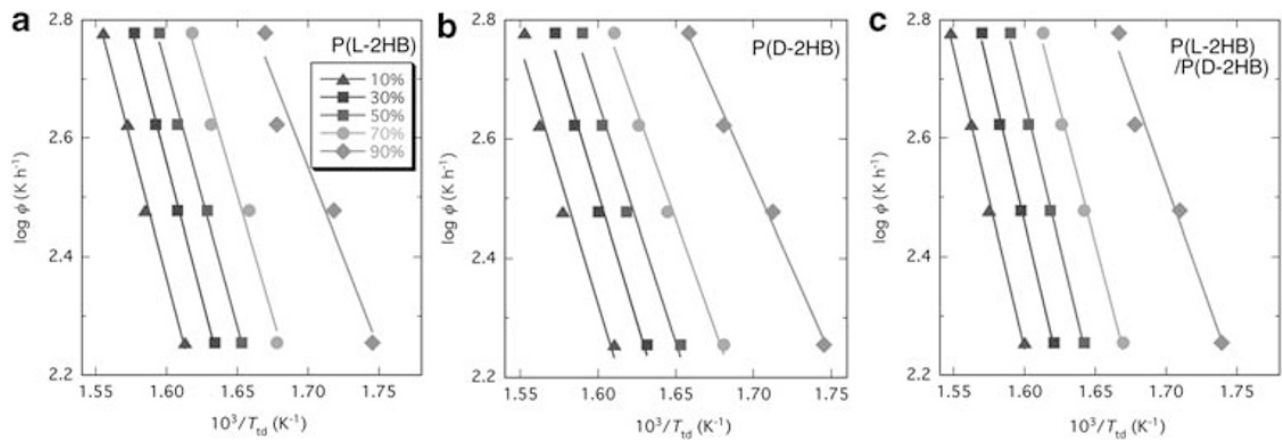

Figure 10 Ozawa's plot of pure $\mathrm{P}(\mathrm{L}-2 \mathrm{HB})(\mathbf{a}), \mathrm{P}(\mathrm{D}-2 \mathrm{HB})(\mathbf{b})$ and their blend (c) for different remaining weight percentages. 
the same configurations; this hindered the thermal cleavage of $\mathrm{P}(2 \mathrm{HB})$ chains in the blend. As depicted in the image on the website of this article, $\mathrm{P}(\mathrm{L}-2 \mathrm{HB})$ and $\mathrm{P}(\mathrm{D}-2 \mathrm{HB})$ chains are assumed to have clockwise and counterclockwise helical structures, respectively. This will facilitate the arrangements of the parent and side chains more appropriate for inter-chain interaction compared with that between the $\mathrm{P}(\mathrm{L}-2 \mathrm{HB})$ or $\mathrm{P}(\mathrm{D}-2 \mathrm{HB})$ chains having the same helical structures.

\section{CONCLUSIONS}

The following conclusions can be derived from the present study for the crystallization and hydrolytic and thermal degradation of the novel stereocomplexationable $\mathrm{P}(\mathrm{L}-2 \mathrm{HB}) / \mathrm{P}(\mathrm{D}-2 \mathrm{HB})$ blend relative to those of pure $\mathrm{P}(\mathrm{L}-2 \mathrm{HB})$ and $\mathrm{P}(\mathrm{D}-2 \mathrm{HB})$. The $G$ and hydrolytic/thermal degradation resistance of the $\mathrm{P}(\mathrm{L}-2 \mathrm{HB}) / \mathrm{P}(\mathrm{D}-2 \mathrm{HB})$ blend were higher than those of pure $\mathrm{P}(\mathrm{L}-2 \mathrm{HB})$ and $\mathrm{P}(\mathrm{D}-2 \mathrm{HB})$. This indicates that the intermolecular interaction between the $\mathrm{P}(\mathrm{L}-2 \mathrm{HB})$ and the $\mathrm{P}(\mathrm{D}-2 \mathrm{HB})$ chains having opposite configurations in the amorphous regions or in the molten state was higher than that between the $\mathrm{P}(\mathrm{L}-2 \mathrm{HB})$ chains or the $\mathrm{P}(\mathrm{D}-2 \mathrm{HB})$ chains with the same configurations. The information obtained in the present study should be very useful for designing and processing biodegradable materials of pure $\mathrm{P}(\mathrm{L}-2 \mathrm{HB}), \mathrm{P}(\mathrm{D}-2 \mathrm{HB})$ and their blends for biomedical, pharmaceutical and environmental applications.

\section{ACKNOWLEDGEMENTS}

We thank Mr Yuzuru Sakamoto of the Department of Environmental and Life Sciences, Graduate School of Engineering at Toyohashi University of Technology for his GPC data analysis. This research was supported by a Grand-in-aid for Scientific Research, Category 'C', No. 19500404, from the Japan Society for the Promotion of Science (JSPS).

1 Kharas, G. B., Sanchez-Riera, F. \& Severson, D. K. in Plastics from Microbes (ed. Mobley, D. P.), 93-137 (Hanser Publishers, New York, 1994).

2 Doi, Y. \& Fukuda, K. (eds) Biodegradable Plastics and Polymers (Elsevier, Amsterdam, 1994).

3 Li, S. \& Vert, M. in Degradable Polymers. Principles and Applications (eds Scott, G. \& Gilead, D.) 43-87, (Chapman \& Hall, London, 1995).

4 Hartmann, M. H. in Biopolymers from Renewable Resources (ed. Kaplan, D. L.) 367-411 (Springer, Berlin, 1998).

5 Ikada, Y. \& Tsuji, H. Biodegradable polyesters for medical and ecological applications. Macromol. Rapid Commun. 21, 117-132 (2000).

6 Garlotta, D. A literature review of poly(lactic acid). J. Polym. Environ. 9, 63-84 (2001).

7 Albertsson, A.- C. (ed.). Degradable Aliphatic Polyesters (Advances in Polymer Science Vol. 157: (Springer, Berlin, 2002).

8 Södergård, A. \& Stolt, M. Properties of lactic acid based polymers and their correlation with composition. Prog. Polym. Sci. 27, 1123-1163 (2002).

9 Scott, G. (ed.) Biodegradable Polymers. Principles and Applications. 2nd edn (Kluwer Academic Publishers, Dordrecht, The Netherlands, 2002).

10 Tsuji, H. in Polyesters 3 (Biopolymers Vol. 4: (eds Doi, Y. \& Steinbüchel, A.) 129-177 (Weinheim (Germany), Wiley-VCH, 2002).
11 Auras, R., Harte, B. \& Selke, S. An overview of polylactides as packaging materials. Macromol. Biosci. 4, 835-864 (2004).

12 Gupta, A. P. \& Kumar, V. New emerging trends in synthetic biodegradable polymers Polylactide: a critique. Eur. Polym. J. 43, 4053-4074 (2007).

13 Slager, J. \& Domb, A. J. Biopolymer stereocomplexes. Adv. Drug Delivery Rev. 55, 549-583 (2003).

14 Tsuji, H. Poly(lactide) stereocomplexes: formation, structure, properties, degradation, and applications. Macromol. Biosci. 5, 569-597 (2005).

15 Fukushima, K. \& Kimura, Y. Stereocomplexed polylactides (Neo-PLA) as high-performance bio-based polymers: their formation, properties, and application. Polym. Int. 55, 626-642 (2006).

16 Tsuji, H. In vitro hydrolysis of blends from enantiomeric poly(lactide)s. 1. Wellstereocomplexed blend and non-blended films. Polymer 41, 3621-3630 (2000).

17 de Jong, S. J., van Eerdenbrugh, B., van Nostrum, C. F., Kettenes-van den Bosch, J. J. \& Hennink, W. E. Physically crosslinked dextran hydrogels by stereocomplex formation of lactic acid oligomers: degradation and protein release behavior. J. Control. Rel. 71, 261-275 (2001).

18 Andersson, S. R., Hakkarainen, M., Inkinen, S., Södergård, A. \& Albertsson, A.- C. Polylactide stereocomplexation leads to higher hydrolytic stability but more acidic hydrolysis product pattern. Biomacromolecules 11, 1067-1073 (2010).

19 Tsuji, H. \& Tsuruno, T. Accelerated hydrolytic degradation of poly(L-lactide)/poly(Dlactide) stereocomplex up to late stage. Polym. Degrad. Stab. 95, 477-484 (2010).

20 Tsuji, H. \& Fukui, I. Enhanced thermal stability of poly(lactide)s in the melt by enantiomeric polymer blending. Polymer 44, 2891-2896 (2003).

21 Tsuji, H. \& Okumura, A. Stereocomplex formation between enantiomeric substituted poly(lactide)s: blends of poly[(S)-2-hydroxybutyrate] and poly[(R)-2-hydroxybutyrate]. Macromolecules 42, 7263-7266 (2009).

22 Tsuji, H., Yamamoto, S., Okumura, A. \& Sugiura, Y. Heterostereocomplexation between biodegradable and optically active polyesters as a versatile preparation method for biodegradable materials. Biomacromolecules 11, 252-258 (2010).

23 Tsuji, H. \& Matsuoka, H. Stereoselective interaction between isotactic and optically active poly(lactic acid) and phenyl-substituted poly(lactic acid). Macromol. Rapid Commun. 29, 1372-1377 (2008).

24 Tsuji, H., Matsuoka, H. \& Itsuno, S. Synthesis, physical properties, and crystallization of optically active poly(L-phenyllactic acid) and poly(L-phenyllactic acid-co-L-lactic acid). J. Appl. Polym. Sci. 110, 3954-3962 (2008).

25 Tsuji, H. \& Tezuka, Y. Stereocomplex formation between enantiomeric poly(lactic acid)s. XII. Spherulite growth of low-molecular-weight poly(lactic acid)s. Biomacromolecules 5, 1181-1186 (2004).

26 Tsuji, H. \& Ikada, Y. Stereocomplex formation between enantiomeric poly(lactic acid)s. 9. Stereocomplexation from the melt. Macromolecules 26, 6918-6926 (1993).

27 Marega, C., Marigo, A., Di Noto, V., Zannetti, R., Martorana, A. \& Paganetto, G. Structure and crystallization kinetics of poly(L-lactic acid). Makromol. Chem. 193, 1599-1606 (1992).

28 Tsuji, H. \& Ikada, Y. Properties and morphologies of poly(L-lactide): 1. Annealing effects on properties and morphologies of poly(L-lactide). Polymer 36, 2709-2716 (1995).

29 Yamane, H . \& Sasai, K . Effect of the addition of poly(d-lactic acid) on the thermal property of poly(l-lactic acid). Polymer 44, 2569-2575 (2003).

30 Bouapao, L. \& Tsuji, H. Stereocomplex crystallization and spherulite growth of lowmolecular-weight poly(L-lactide) and poly(D-lactide) from the melt. Macromol. Chem. Phys. 210, 993-1002 (2009).

31 Tsuji, H. Degradation of Poly(lactide)-Based Biodegradable Materials (Nova Science Publishers, New York, 2007).

32 Tsuji, H. in Biodegradable Polymers for Skeletal Implants (eds Wuisman, P. I. J. M. \& Smit, T. H.) 41-71 (Nova Science Publishers, New York, 2009).

33 Tsuji, H. in Poly(lactic acid): Synthesis, Structures, Properties, Processing, and Applications (eds Auras, R., Lim, L. -T., Selke, S. \& Tsuji, H.) 345-381 (John Wiley and Sons, NJ, 2010).

34 Karst, D. \& Yang, Y. Effect of arrangement of L-lactide and D-lactide in poly[(L-lactide)co-(D-lactide)] on its resistance to hydrolysis studied by molecular modeling. Macromol. Chem. Phys. 209, 168-174 (2008).

35 Ozawa, T. A new method of analyzing thermogravimotric data. Bull. Chem. Soc. Jpn $\mathbf{3 8}$, 1881-1886 (1965). 